\title{
Favipiravir use in children with COVID-19 and acute kidney injury: is it safe?
}

\author{
Yasemin Ozsurekci ${ }^{1}$ - Pembe Derin Oygar ${ }^{1}$ - Sibel Laçinel Gürlevik ${ }^{1} \cdot$ Selman Kesici ${ }^{2} \cdot$ Seza Ozen $^{3}$. \\ Eda Didem Kurt Sukur ${ }^{4} \cdot$ Bora Gülhan $^{4} \cdot$ Rezan Topaloglu $^{4} \cdot$ Benan Bayrakci $^{2} \cdot$ Ali Bülent Cengiz $^{1}$
}

Received: 4 March 2021 / Revised: 11 April 2021 / Accepted: 29 April 2021

(C) IPNA 2021, corrected publication 2021

\begin{abstract}
Background The rising number of infections due to Severe Acute Respiratory Syndrome Coronavirus-2 (popularly known as COVID-19) has brought to the fore new antiviral drugs as possible treatments, including favipiravir. However, there is currently no data regarding the safety of this drug in patients with kidney impairment. The aim of this paper, therefore, is to share our experience of the use of favipiravir in pediatric patients affected by COVID-19 with any degree of kidney impairment.

Methods The study enrolled pediatric patients aged under 18 years and confirmed as suffering from COVID-19 and multisystem inflammatory syndrome in children (MIS-C) with any degree of kidney injury, who were treated with favipiravir at the time of admission.

Results Out of a total of 11 patients, 7 were diagnosed with MIS-C and 4 with severe COVID-19. The median age of the cases was $15.45(9-17.8)$ years and the male/female ratio was 7/4. At the time of admission, the median serum creatinine level was 1.1 $\mathrm{mg} / \mathrm{dl}$. Nine patients were treated with favipiravir for 5 days, and 2 patients for 5 days followed by remdesivir for $5-10$ days despite kidney injury at the time of admission. Seven patients underwent plasma exchange for MIS-C while 2 severely affected cases underwent continuous kidney replacement therapy (CKRT) as well. One severe COVID-19 patient received plasma exchange as well as CKRT. Serum creatinine values returned to normal in mean 3.07 days.

Conclusions Favipiravir seems a suitable therapeutic option in patients affected by COVID-19 with kidney injury without a need for dose adjustment.
\end{abstract}

Keywords Favipiravir $\cdot$ Remdesivir $\cdot$ SARS-CoV-2 $\cdot$ COVID-19 $\cdot$ Pediatrics

\section{Introduction}

The year 2019 saw the outbreak of a novel Severe Acute Respiratory Syndrome Coronavirus-2 (SARS-CoV-2 or COVID-19) and associated diseases. Subsequently, an increasing

Yasemin Ozsurekci

yas.oguz99@yahoo.com

1 Department of Pediatric Infectious Diseases, Faculty of Medicine, Hacettepe University, Ankara, Turkey

2 Division of Pediatric Intensive Care Unit, Department of Pediatrics, Faculty of Medicine, Hacettepe University, Ankara, Turkey

3 Division of Pediatric Rheumatology, Department of Pediatrics, Faculty of Medicine, Hacettepe University, Ankara, Turkey

4 Division of Pediatric Nephrology, Department of Pediatrics, Faculty of Medicine, Hacettepe University, Ankara, Turkey number of cases of multisystem inflammatory syndrome in children (MIS-C) were reported as a new entity temporally associated with COVID-19. These new entities have led us to use new antiviral drugs and immune modulators. Furthermore, many patients requiring treatment for COVID-19 and/or associated diseases may have a preexisting kidney disorder or experience acute kidney injury (AKI) as a result of the infection. Although worldwide evidence shows that COVID-19 commonly has a milder clinical course in children [1-4], some of them still develop severe/critical disease, as was the case in our pediatric cohort [5]. In general, except in severely affected cases, we preferred to use supportive treatment in children with COVID-19. In Turkey, favipiravir is one of the available drugs for the treatment of COVID-19 and is recommended by the Turkish Ministry of Health for severe pediatric COVID-19 cases.

Favipiravir is a nucleotide analog that inhibits RNA polymerase and has been approved for the treatment of influenza in China and Japan. It is a hydrophilic molecule with a 
protein-bound fraction around $50 \%$ and a distribution volume between 15 and 201 . The drug is used orally and rapidly absorbed with a $t_{\max }$ ranging from 30 to $60 \mathrm{~min}$ as well as a high bioavailability of about $100 \%[6,7]$.

Adverse reactions including hyperuricemia, gastrointestinal symptoms (e.g., diarrhea, nausea, vomiting, and abdominal pain), increased alanine transaminase (ALT) and aspartate transaminase (AST), and decreased white blood cell and neutrophil counts have been seen in approximately $20 \%$ of patients who received favipiravir. Also, a positive association between favipiravir use and QTc prolongation has been reported, which is still unclear [7-9]. There is thus a lack of knowledge about the longer-term effects of the treatment and more evidence is needed. However, favipiravir has an overall good safety profile [8] and has recently been studied and registered for COVID-19 also in Japan.

The major elimination pathway of the drug is the kidney and inactive metabolites produced by aldehyde oxidase and xanthine oxidase are excreted in the urine. Favipiravir has time- and dose-dependent pharmacokinetics based on the inhibition of aldehyde oxidase [7]. However, there is a lack of data in the literature on favipiravir metabolism with decreased kidney function, which can significantly affect the drug serum concentration. So far it has not been possible to make a recommendation for its safe use in patients with kidney impairment, particularly children $[5,10]$. Here we aim to share our experiences with favipiravir use in children affected by SARS-CoV-2 with any degree of AKI.

\section{Methods}

We recruited pediatric patients under 18 years of age and confirmed as suffering from COVID-19 and/or MIS-C with any degree of kidney injury who were treated with favipiravir at the time of admission, between March 26 and December 30, 2020. Review of the clinical features of children with COVID19 and MIS-C have been approved by the institutional review boards at Hacettepe University and the University of Health Sciences, Ankara Educating and Training Hospital. All of the patients' parents/legal guardians provided written informed consent for the use of favipiravir or remdesivir according to the regulations of the Turkish Ministry of Health.

Suspicious cases with positive reverse transcriptasepolymerase chain reaction (RT-PCR) or serum-specific antibodies against 2019-nCoV were accepted as confirmed cases [11]. The severity of pediatric COVID-19 was classified based on the clinical characteristics and laboratory and radiologic investigation results defined by Dong et al. [12]. Severe/ critical disease was defined as progressive respiratory disease or respiratory failure, shock, and organ dysfunction. The children were diagnosed as MIS-C according to CDC criteria [13] and/or WHO definitions [14]. Acute kidney injury was classified according to the Kidney Disease Improving Global Outcomes (KDIGO) classification [15]. Bedside Schwartz formula was used to calculate estimated GFR levels [16].

The variables potentially associated with COVID-19 infection and MIS-C were listed as follows: age; sex; clinical presentation; previous medical history; underlying diseases; duration of symptoms; findings of organ involvement; laboratory investigations such as white blood cell count (WBC), acute phase reactants, kidney and liver function tests, electrolytes, albumin, and radiologic findings such as posteroanterior chest $\mathrm{X}$-ray, abdominal ultrasonography, and chest computed tomography $(\mathrm{CT})$ if needed; use of central venous catheters and mechanical ventilation; antiviral and antimicrobial treatments; immunosuppressive and immunomodulatory treatments; side effects of treatments; the need for plasma exchange or kidney replacement therapy (KRT); pediatric ICU (PICU) admission; and outcome. Data regarding the demographic and clinical characteristics of patients were collected via patients' charts and the digital administrative, pharmacy, and laboratory databases of the hospital.

\section{Treatment modalities}

During the pandemic, only severe and critically ill pediatric cases were hospitalized and treated with an antiviral agent. Favipiravir was the main antiviral agent available at our center and was used together with antimicrobial treatments after hospitalization. Remdesivir was very difficult to obtain and could only be used after the treatment with favipiravir in a handful of patients. Favipiravir was given orally on a weight-based dosing as per the recommended treatment for Ebola [17]. In patients weighing $22-35 \mathrm{~kg}$, the first dose was administered as $1200 \mathrm{mg}$, followed by another $1200 \mathrm{mg}$ after $8 \mathrm{~h}$, and then by $600 \mathrm{mg} 16 \mathrm{~h}$ after the first dose. On $2 \mathrm{nd}-4$ th days, $600 \mathrm{mg}$ every $12 \mathrm{~h}$ was administered. For patients weighing $36-45 \mathrm{~kg}$, the initial dose was $1200 \mathrm{mg}$, followed by another $1200 \mathrm{mg}$ after $8 \mathrm{~h}$, and then by $800 \mathrm{mg} 16 \mathrm{~h}$ after the first dose. On 2nd4th days, $800 \mathrm{mg}$ every $12 \mathrm{~h}$ was administered. For those in the $46-55 \mathrm{~kg}$ weight range, the initial and the 8 -h doses were $2000 \mathrm{mg}$, followed by $1000 \mathrm{mg}$ at the 16th hour, while the 2nd-4th-day doses were $1000 \mathrm{mg}$ every $12 \mathrm{~h}$. Patients weighing $>55 \mathrm{~kg}$ received an initial dose of $2400 \mathrm{mg}$, followed by $2400 \mathrm{mg}$ at the 8 th hour, and by $1200 \mathrm{mg}$ at the 16 th hour, and then $1200 \mathrm{mg}$ every $12 \mathrm{~h}$ on $2 \mathrm{nd}-4$ th days [18]. Remdesivir was administered as an intravenous infusion over 30-120 min. Patients weighing less than $40 \mathrm{~kg}$ were given a single loading dose of $5 \mathrm{mg} / \mathrm{kg}$ on day 1 followed by 2.5 $\mathrm{mg} / \mathrm{kg}$ once daily as of day 2 . Patients weighing $40 \mathrm{~kg}$ and more were given a single loading dose of $200 \mathrm{mg}$ on day 1 followed by once-daily maintenance doses of $100 \mathrm{mg}$ from day 2 [19]. 
Anakinra was used $2 \mathrm{mg} / \mathrm{kg} / \mathrm{dose}$ subcutaneously twice daily. A single dose of intravenous (IV) immunoglobulin (IVIG) $2 \mathrm{~g} / \mathrm{kg}$ was also infused over $24 \mathrm{~h}$ and IV methylprednisolone was given at $1-2 \mathrm{mg} / \mathrm{kg} /$ dose twice daily for MIS-C cases.

Plasma exchange was performed for removal of possible soluble cytokines/chemokines during the cytokine storm and continuous renal replacement therapy (CKRT) was performed in patients when needed. The dose of favipiravir for patients who underwent CKRT was not changed. Continuous venovenous hemodialysis (CVVHD) was preferred in our center for critically ill, clinically unstable patients.

\section{Results}

Out of a total of 11 patients, 7 were diagnosed with MIS-C and 4 with severe COVID-19. The median age of the cases was 15.45 (min-max, 9-17.8) years and the male/female ratio was $7 / 4$. At the time of admission, the median serum creatinine and GFR levels were $1.1 \mathrm{mg} / \mathrm{dl}$ (min-max, 0.84-3.54 mg/dl) and $75.63 \mathrm{ml} / \mathrm{min} / 1.73 \mathrm{~m}^{2}$ (min-max, 26.1-103.8 ml/min/1.73 $\mathrm{m}^{2}$ ), respectively, while at discharge the median creatinine level was $0.48 \mathrm{mg} / \mathrm{dl}(\min -\max , 0.16-0.71 \mathrm{mg} / \mathrm{dl})$ and the median GFR level $137.66 \mathrm{ml} / \mathrm{min} / 1.73 \mathrm{~m}^{2}$ (min-max, 98.8$159 \mathrm{ml} / \mathrm{min} / 1.73 \mathrm{~m}^{2}$ ). Nine patients were treated with favipiravir for 5 days, and 2 patients for 5 days followed by remdesivir for 5-10 days despite kidney injury at the time of admission (Table 1). No adverse side effects associated with favipiravir were observed.

All MIS-C patients underwent plasma exchange and 2 of them who were severely affected underwent CKRT as well. One severe COVID-19 patient underwent both plasma exchange and CKRT and received favipiravir before plasma exchange. Six MIS-C patients were treated with favipiravir after plasma exchange and 1 patient with MIS-C received favipiravir before plasma exchange but the repeat dose was not administered. The duration of plasmapheresis was $1-1.5 \mathrm{~h}$ per session and each patient underwent plasma exchange only once except for one case in which plasmapheresis was performed four times. Four patients, 2 of whom had plasma exchange at the same time as or after the drug's administration (which could potentially remove the drug) and 2 who needed CKRT (which could remove the drug due to its low protein binding), were excluded and the analysis repeated. The median serum creatinine and eGFR levels of the remaining 7 patients at the time of admission were $0.9 \mathrm{mg} / \mathrm{dl}$ and $82.5 \mathrm{ml} /$ $\min / 1.73 \mathrm{~m}^{2}$, respectively. Their discharge levels were 0.49 $\mathrm{mg} / \mathrm{dl}$ and $135.91 \mathrm{ml} / \mathrm{min} / 1.73 \mathrm{~m}^{2}$.

Serum creatinine values returned to normal in 3.07 days on average (Fig. 1). Three out of 4 severe COVID-19 patients had underlying diseases; 1 had testicular cancer and was receiving chemotherapy, 1 had hyperlipidemia and type 2 diabetes mellitus (DM), and 1 had type $1 \mathrm{DM}$ and was admitted with diabetic ketoacidosis. None of the MIS-C patients had comorbidities. None of the patients of the cohort had any preexisting kidney disease. All patients were discharged except 1 who is still hospitalized.

\section{Discussion}

Remdesivir, favipiravir, lopinavir/ritonavir, hydroxychloroquine, azithromycin, corticosteroids, tocilizumab, and anakinra have been identified as experimental drugs for the treatment of COVID-19 in Turkey as in many other parts of the world [10]. Asymptomatic, mild, and moderate cases constituted $95 \%$ of COVID-19 cases in our center [5], which is one of the largest tertiary care centers in Turkey, receiving referrals from both Anatolia and its southeastern neighbors. Our COVID-19 management protocol suggests that only severely affected children should be treated with targeted therapies. It should be noted that therapeutic options were limited by the availability of drugs in our country. We preferred not to use lopinavir/ritonavir, hydroxychloroquine, and azithromycin, given conflicting data in the literature [5, 20-22]. Remdesivir is not easily available in Turkey and we could use it only for a few cases. Favipiravir is more readily available and despite the lack of clinical evidence in children, we had to use it in patients with some degree of kidney or hepatic impairment. We used favipiravir in our severely affected cases with kidney impairment without any dose adjustment. Moreover, remdesivir was used sequentially for two cases in our cohort at full dose. In light of ongoing clinical trials in India and the USA [23], Marra et al. [10] recommend that dose adjustment should be considered for favipiravir in COVID-19 patients with kidney impairment. M1 is the hydrophilic and inactive metabolite whose accumulation in reduced GFR might be related to drug toxicity. In an ongoing clinical study that includes 30 patients with eGFRs between 50 and 80 $\mathrm{ml} / \mathrm{min} / 1.73 \mathrm{~m}^{2}$, no pharmacokinetic data for favipiravir is presented [2]. Furthermore, there is no data to make safety statements about the drug's use in patients with kidney impairment or on KRT [10]. We used favipiravir for our 2 pediatric cases with eGFR $<30 \mathrm{ml} / \mathrm{min} / 1.73 \mathrm{~m}^{2}$ and it was well tolerated.

After the lungs, the kidneys are one of the major organs affected in severe COVID-19 associated with a poor outcome. The pathophysiology of acute kidney injury in COVID-19 is unclear but there may be a multi-factorial mechanism including complex interactions between host and virus, hemodynamic alterations, the effect of intensive therapies such as invasive mechanical ventilation on kidney blood flow as well as nephrotoxic drugs $[24,25]$. There is also scarce data to predict the accurate organ damage related to these new drugs. In India, acute kidney injury was reported in two males, aged 
Table 1 Clinical features of cases with COVID-19 and acute kidney injury

\begin{tabular}{|c|c|c|c|c|c|c|c|c|}
\hline $\begin{array}{l}\text { Case } \\
\text { No. }\end{array}$ & $\begin{array}{l}\text { Age } \\
\text { (yr) }\end{array}$ & Sex & Diagnosis & Antiviral & Underlying disease & $\begin{array}{l}\text { Serum } \mathrm{Cr} \text { levels at the } \\
\text { time of the admission } \\
(\mathrm{mg} / \mathrm{dl}) / \mathrm{eGFR} \\
\left(\mathrm{ml} / \mathrm{min} / 1.73 \mathrm{~m}^{2}\right)\end{array}$ & $\begin{array}{l}\text { Duration of elevated } \\
\text { Cr levels (days) }\end{array}$ & Intervention \\
\hline 1 & 15.9 & M & COVID-19 & Favi & Testicular carcinoma & $0.85 / 103.89$ & 2 & None \\
\hline 2 & 15.8 & M & MIS-C & Favi & None & $1.1 / 75.63$ & 3 & Plasma exchange \\
\hline 3 & 14.5 & $\mathrm{~F}$ & MIS-C & Favi and $\mathrm{R}$ & None & $1.5 / 60.5$ & 5 & Plasma exchange and CKRT \\
\hline 4 & 13.0 & $\mathrm{~F}$ & MIS-C & Favi & Hyperlipidemia/DM2 & $3.26 / 26.15$ & 7 & Plasma exchange and CKRT \\
\hline 5 & 17.8 & $\mathrm{~F}$ & COVID-19 & Favi and $\mathrm{R}$ & None & $3.54 / 26.41$ & 7 & Plasma exchange and CKRT \\
\hline 6 & 16.8 & M & MIS-C & Favi & None & $1.2 / 77.92$ & 2 & Plasma exchange \\
\hline 7 & 15.1 & M & COVID-19 & Favi & None & $0.84 / 85$ & 4 & None \\
\hline 8 & 12.2 & M & COVID-19 & Favi & DM1 & $0.91 / 96.70$ & 2 & None \\
\hline 9 & 17.6 & M & MIS-C & Favi & Sensorineural hearing loss & $0.96 / 63$ & 4 & Plasma exchange \\
\hline 10 & 9.5 & $\mathrm{~F}$ & MIS-C & Favi & Hyperlipidemia & $1.45 / 59.6$ & 3 & Plasma exchange \\
\hline 11 & 9.0 & M & MIS-C & Favi & None & $0.9 / 82.5$ & 2 & Plasma exchange \\
\hline
\end{tabular}

Favi, favipiravir; $M I S-C$, multisystemic inflammatory syndrome in children; $C K R R T$, continuous kidney replacement therapy, $R$ remdesivir

38 and 51, who were treated with favipiravir due to severe COVID-19, which resolved after favipiravir was discontinued [26]. It is difficult to establish a cause-effect relationship in patients with severe/critical disease. Data is lacking on favipiravir dosage and dose adjustment according to glomerular filtration rate in patients with acute kidney injury or chronic kidney disease [27], particularly in children. Despite the scarcity of data, during the pandemic we often found ourselves needing to use these drugs in an off-label manner. Based on this experience, we wanted to share our data about pediatric patients with impaired kidney function. The literature does not recommend skipping the loading dose in patients with GFRs ranging from 30 to $50 \mathrm{ml} / \mathrm{min} / 1.73 \mathrm{~m}^{2}$ since the expected two- to three-fold increase in plasma drug levels is considered safe [28]. In the present study, favipiravir was used at full dose and was well tolerated with no major side effects. Larger and prospective studies are required to clarify the need for dose adjustment of these drugs in case of kidney impairment.

There are at least two limitations in our study. First, we had no chance to investigate the plasma levels of favipiravir. Second, in 2 patients the plasma levels of favipiravir might have been affected by plasma exchange.

In conclusion, favipiravir might be a suitable therapeutic option in pediatric SARS-CoV-2 patients with reduced GFR
Fig. 1 Creatinine levels of the patients from presentation to day 7 of hospitalization

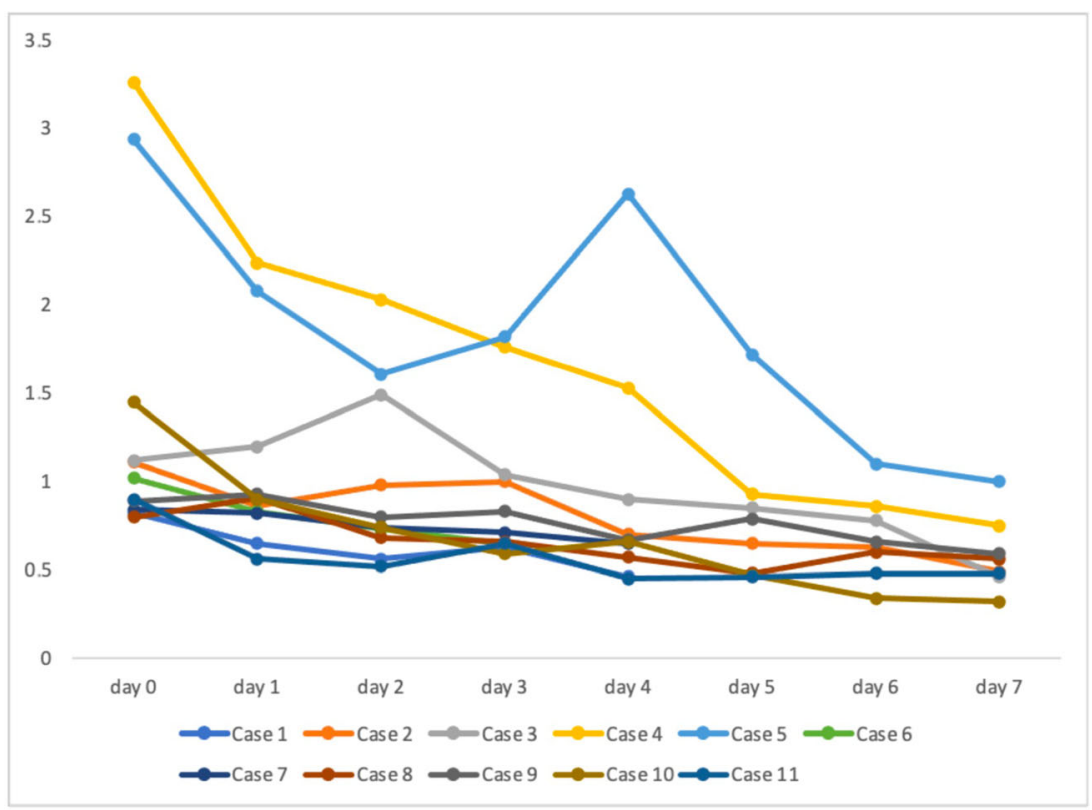


without a need for dose adjustment. Larger studies that include the measurement of plasma levels of favipiravir are needed. Despite the small sample size and the lack of data on plasma favipiravir levels, when we consider the limited knowledge and experience in the field, we believe that our findings might guide clinicians treating patients with COVID-19 and associated diseases in the pandemic.

Supplementary Information The online version contains supplementary material available at https://doi.org/10.1007/s00467-021-05111-x.

Author contribution Conception: YO, PDO, SLG, SO, ABC. Design: YO, RT, ABC, BB. Data collection and/or processing: YO, PDO, SLG, SK, EDSK, BG. Analysis and/or interpretation: YO, ABC, RT, BG, BB, SO. Literature review: YO, PDO, ABC. Writer: YO, PDO. Critical review: YO, ABC, RT.

\section{Declarations}

Conflict of interest The authors declare no competing interests.

\section{References}

1. Castagnoli R, Votto M, Licari A, Brambilla I, Bruno R, Perlini S, Rovida F, Baldanti F, Marseglia GL (2020) Severe acute respiratory syndrome coronavirus 2 (SARS-CoV-2) infection in children and adolescents: a systematic review. JAMA Pediatr 174:882-889

2. Rodriguez-Morales AJ, Cardona-Ospina JA, Gutierrez-Ocampo E, Villamizar-Pena R, Holguin-Rivera Y, Escalera-Antezana JP, Alvarado-Arnez LE, Bonilla-Aldana DK, Franco-Paredes C, Henao-Martinez AF, Paniz-Mondolfi A, Lagos-Grisales GJ, Ramirez-Vallejo E, Suarez JA, Zambrano LI, Villamil-Gomez WE, Balbin-Ramon GJ, Rabaan AA, Harapan H, Dhama K, Nishiura H, Kataoka H, Ahmad T, Sah R, Latin American Network of Coronavirus Disease 2019-COVID-19 Research (LANCOVID-19) (2020) Clinical, laboratory and imaging features of COVID-19: a systematic review and meta-analysis. Travel Med Infect Dis 34:101623

3. Ludvigsson JF (2020) Systematic review of COVID-19 in children shows milder cases and a better prognosis than adults. Acta Paediatr 109:1088-1095

4. Lu X, Zhang L, Du H, Zhang J, Li YY, Qu J, Zhang W, Wang Y, Bao S, Li Y, Wu C, Liu H, Liu D, Shao J, Peng X, Yang Y, Liu Z, Xiang Y, Zhang F, Silva RM, Pinkerton KE, Shen K, Xiao H, Xu S, Wong GWK (2020) SARS-CoV-2 infection in children. N Engl J Med 382:1663-1665

5. Cura Yayla BC, Ozsurekci Y, Aykac K, Derin Oygar P, Lacinel Gurlevik S, İlbay S, Kukul MG, Karahan S, Cengiz AB, Ceyhan M (2020) Characteristics and management of children with COVID19 in Turkey. Balkan Med J 37:341-347

6. Nguyen THT, Guedj J, Anglaret X, Laouenan C, Madelain V, Taburet AM, Baize S, Sissoko D, Pastorino B, Rodallec A, Piorkowski G, Carazo S, Conde MN, Gala JL, Bore JA, Carbonnelle C, Jacquot F, Raoul H, Malvy D, Lamballerie X, Mentre F, JIKI study group (2017) Favipiravir pharmacokinetics in Ebola-infected patients of the JIKI trial reveals concentrations lower than targeted. PLoS Negl Trop Dis 11:e0005389
7. Japanese Pharmaceuticals and Medical Devices Agency (PMDA) (2014) Report on the deliberation results. https://www.pmda.go.jp/ files/000210319.pdf. Accessed 26 March 2021

8. Pilkington V, Repperel T, Hill A (2020) A review of the safety of favipiravir - a potential treatment in the COVID-19 pandemic? J Virus Erad 6:45-51

9. Kumagai Y, Murakawa Y, Hasunama T, Aso M, Yuji W, Sakurai T, Noto M, Oe T, Kaneko A (2015) Lack of effect of favipiravir, a novel antiviral agent, on the QT interval in healthy Japanese adults. Int J Clin Pharm Ther 53:866-874

10. Marra F, Smolders EJ, El-Sherif O, Boyle A, Davidson K, Sommerville AJ, Marzolini C, Siccardi M, Burger D, Gibbons S, Khoo S, Back D (2021) Recommendations for dosing of repurposed COVID-19 medications in patients with renal and hepatic impairment. Drugs R\&D 21:9-27

11. Shen KL, Yang YH, Jiang RM, Wang TY, Zhao DC, Jiang Y, Lu XX, Jin RM, Zheng YJ, Xu BP, Xie ZD, Liu ZS, Li XW, Lin LK, Shang YX, Shu SN, Bai Y, Lu M, Lu G, Deng JK, Luo WJ, Xiong LJ, Liu M, Cui YX, Ye LP, Li JF, Shao JB, Gao LW, Wang YY, Wang XF (2020) Updated diagnosis, treatment and prevention of COVID-19 in children: experts' consensus statement (condensed version of the second edition). World J Pediatr 16:232-239

12. Dong Y, Mo X, Hu Y, Qi X, Jaing F, Jiang Z, Tong S (2020) Epidemiological characteristics of 2143 pediatric patients with 2019 coronavirus disease in China. Pediatrics 58:712-713

13. Centers for Disease Control and Prevention (2020) Multisystem inflammatory syndrome in children (MIS-C) associated with coronavirus disease 2019 (COVID-19). https://emergency.cdc.gov/han/ 2020/han00432.asp. Accessed 10 November 2020

14. World Health Organization (2020) Multisystem inflammatory syndrome in children and adolescents with COVID-19. www.who.int/ publications-detail/multisystem-inflammatory-syndrome-inchildren-and-adolescents-with-covid-19. Accessed 10 November 2020

15. Laycock J, Baum M, Rees L (2020) KDIGO nomenclature glossary for pediatric nephrology. Pediatr Nephrol 35:2201-2203

16. Muhari-Stark E, Burckart GJ (2018) Glomerular filtration rate estimation formulas for pediatric and neonatal use. J Pediatr Pharmacol Ther 23:424-431

17. Bouazza N, Treluyer JM, Foissac F, Mentre F, Taburet AM, Guedj J, Anglaret X, Lamballerie X, Keita S, Malvy D, Frange P (2015) Favipiravir for children with Ebola. Lancet 385:603-604

18. Toyama Chemical Company (2017) Favipiravir (Avigan). Drug insert. https://www.cdc.gov.tw/File/Get/ht8jUiB MIaKnlwstwzvw. Accessed 28 January 2020

19. United States Food and Drug Administration (FDA) (2020) Emergency use authorization (EUA). Fact sheet for healthcare providers emergency use authorization (EUA) of Veklury ${ }^{\circledR}$ (remdesivir) for hospitalized pediatric patients weighing $3.5 \mathrm{~kg}$ to less than $40 \mathrm{~kg}$ or hospitalized pediatric patients less than 12 years of age weighing at least $3.5 \mathrm{~kg}$. https://www.fda.gov/media/ 137566/download. Accessed 27 March 2021

20. Cao B, Wang Y, Wen D, Liu W, Wang J, Fan G, Ruan L, Song B, Cai Y, Wei M, Li X, Xia J, Chen N, Xiang J, Yu T, Bai T, Xie X, Zhang L, Li C, Yuan Y, Chen H, Li H, Huang H, Tu S, Gong F, Liu Y, Wei Y, Dong C, Zhou F, Gu X, Xu J, Liu Z, Zhang Y, Li H, Shang L, Wang K, Li K, Zhou X, Dong X, Qu Z, Lu S, Hu X, Ruan S, Luo S, Wu J, Peng L, Cheng F, Pan L, Zou J, Jia C, Wang J, Liu X, Wang S, Wu X, Ge Q, He J, Zhan H, Qiu F, Guo L, Huang C, Jaki T, Hayden FG, Horby PW, Zhang D, Wang C (2020) A trial of lopinavir-ritonavir in adults hospitalized with severe Covid-19. N Engl J Med 382:1787-1799

21. Geleris J, Sun Y, Platt J, Zucker J, Baldwin M, Hripcsak G, Labella A, Manson DK, Kubin C, Barr RG, Sobieszcyk ME, Schluger NW (2020) Observational study of hydroxychloroquine in hospitalized patients with Covid-19. N Engl J Med 382:2411-2418 
22. Rosenberg ES, Dufort EM, Udo T, Wilberschied LA, Kumar J, Tesoriero J, Weinberg P, Kirkwood J, Muse A, DeHovitz J, Blog DS, Hutton B, Holtgrave DR, Zucker HA (2020) Association of treatment with hydroxychloroquine or azithromycin with inhospital mortality in patients with COVID-19 in New York State. JAMA 323:2493-2502

23. Du YX, Chen XP (2020) Favipiravir: pharmacokinetics and concerns about clinical trials for 2019-nCoV Infection. Clin Pharmacol Ther 108:242-247

24. Hirsch JS, Ng JH, Ross DW, Sharma P, Shah HH, Barnett RL, Hazzan AD, Fishbane S, Jhaveri KD (2020) Acute kidney injury in patients hospitalized with COVID-19. Kidney Int 98:209-218

25. Gabarre P, Dumas G, Dupont T, Darmon M, Azoulay E, Zafrani L (2020) Acute kidney injury in critically ill patients with COVID-19. Intensive Care Med 46:1339-1348
26. Medical Dialogues Bureau (2021) Favipiravir use in COVID-19 patients may lead to nephrotoxicity: case study. https:// medicaldialogues.in/medicine/news/favipiravir-use-in-covid-19patients-may-lead-to-nephrotoxicity-case-study-73398. Accessed 28 January 2021

27. Izzedine H, Jhaveri KD, Perazelli MA (2020) COVID-19 therapeutic options for patients with kidney disease. Kidney Int 7:12971298

28. Sise ME (2020) Pharmacologic treatment of COVID-19: what nephrologists need to know. https://advances.massgeneral.org/ research-and-innovation/article.aspx? $\mathrm{id}=1224$. Accessed 28 January 2021

Publisher's note Springer Nature remains neutral with regard to jurisdictional claims in published maps and institutional affiliations. 